\title{
Intravenous leiomyomatosis with intracardiac extension managed by one- stage surgical excision: a case presentation
}

\author{
Rohit Bhoil', Vijay Thakur ${ }^{1}$, Yashwant Singh Verma², Sabina Bhoil ${ }^{2^{*}}$, Ashwani Tomar ${ }^{1}$, Rajnish Pathania ${ }^{3}$ and \\ Sanjeev Sharma'
}

\begin{abstract}
Background: Intravenous leiomyomatosis is characterized by the extension of pathologically benign smooth muscle tumor into venous channels. Its extension into the heart is a very rare occurrence, which may lead to heart failure and occasionally sudden death. Due to its rarity, the condition is poorly understood and often misdiagnosed.

Case presentation: We report a case of intravenous leiomyomatosis with intracardiac extension in a 40 years old woman who underwent hysterectomy for uterine leiomyoma (one year earlier), managed successfully through onestage surgical approach with main focus on its imaging features.

Conclusion: The diagnosis of intravenous leiomyomatosis should be considered in women who present with cardiac symptoms associated with a right atrial mass and who also have a pelvic mass or have previously undergone hysterectomy because of uterine leiomyoma.
\end{abstract}

Keywords: Intravenous leiomyomatosis, Cardiac extension, Leiomyoma, IVC thrombus, Sudden death

\section{Background}

Intracardiacleiomyomatosis (ICLM), a condition not commonly seen, is characterized by pathologically benign smooth muscle tumor of extracardiac origin reaching up to the right heart by direct extension into the venous channel(s) [1].

It has been postulated that this tumor originates either from a uterine leiomyoma that has invaded the vessels or from the smooth muscle wall of the veins itself [1-3]. Cardiac involvement by extension has been reported in approximately $10 \%$ of leiomyomatosis cases [4]. Cardiac involvement is often confused with a primary cardiac tumor or migrant venous thrombus $[4,5]$.

The case of intravenous leiomyomatosis with cardiac extension was first reported by Birch Hirchfeld in 1897 [6]. According to Liu et al., by 2009 there were about 110 cases of ICLM [7]. We describe a case of intravenous

\footnotetext{
* Correspondence: sabinabhoil@gmail.com

${ }^{2}$ Department of cardiac-anaesthesia, IGMC, Shimla, India

Full list of author information is available at the end of the article
}

leiomyomatosis with intracardiac extension in a 40 years old woman who underwent hysterectomy (1 year earlier) for uterine leiomyoma, which was managed successfully through one-stage surgical approach.

We obtained consent from the patient to publish this case.

\section{Case presentation}

A 40-year-old female with a history of total abdominal hysterectomy for uterine leiomyoma 1 year back, presented with chief complaints of gradually increasing heaviness and distension of abdomen, edema feet, and decreased appetite since the last 3 months. She had dyspnea on exertion and had two episodes of syncope for the last 3 months. Her routine blood tests revealed proteinuria and mildly elevated liver enzymes.

Ultrasound abdomen findings were suggestive of mild hepatomegaly and dilated common iliac vein and inferior vena cava with IVC thrombus showing partial recanalization with extension into the right heart (Fig.1 and

\section{Springer Open}

(ㅇ The Author(s). 2020 Open Access This article is licensed under a Creative Commons Attribution 4.0 International License, which permits use, sharing, adaptation, distribution and reproduction in any medium or format, as long as you give appropriate credit to the original author(s) and the source, provide a link to the Creative Commons licence, and indicate if changes were made. The images or other third party material in this article are included in the article's Creative Commons licence, unless indicated otherwise in a credit line to the material. If material is not included in the article's Creative Commons licence and your intended use is not permitted by statutory regulation or exceeds the permitted use, you will need to obtain permission directly from the copyright holder. To view a copy of this licence, visit http://creativecommons.org/licenses/by/4.0/. 


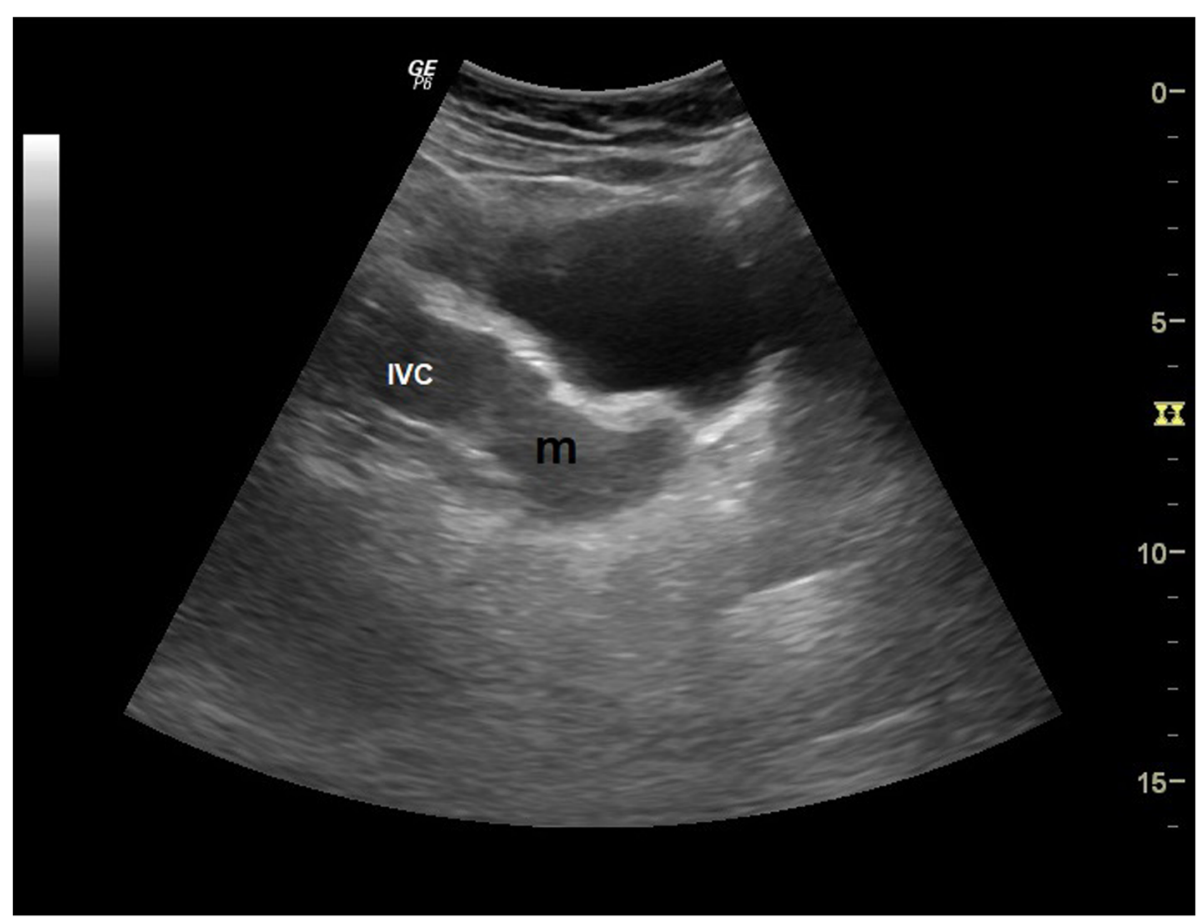

Fig. 1 Oblique grayscale ultrasound image showing the extension of intra-mural thrombus (in IVC) into the right heart

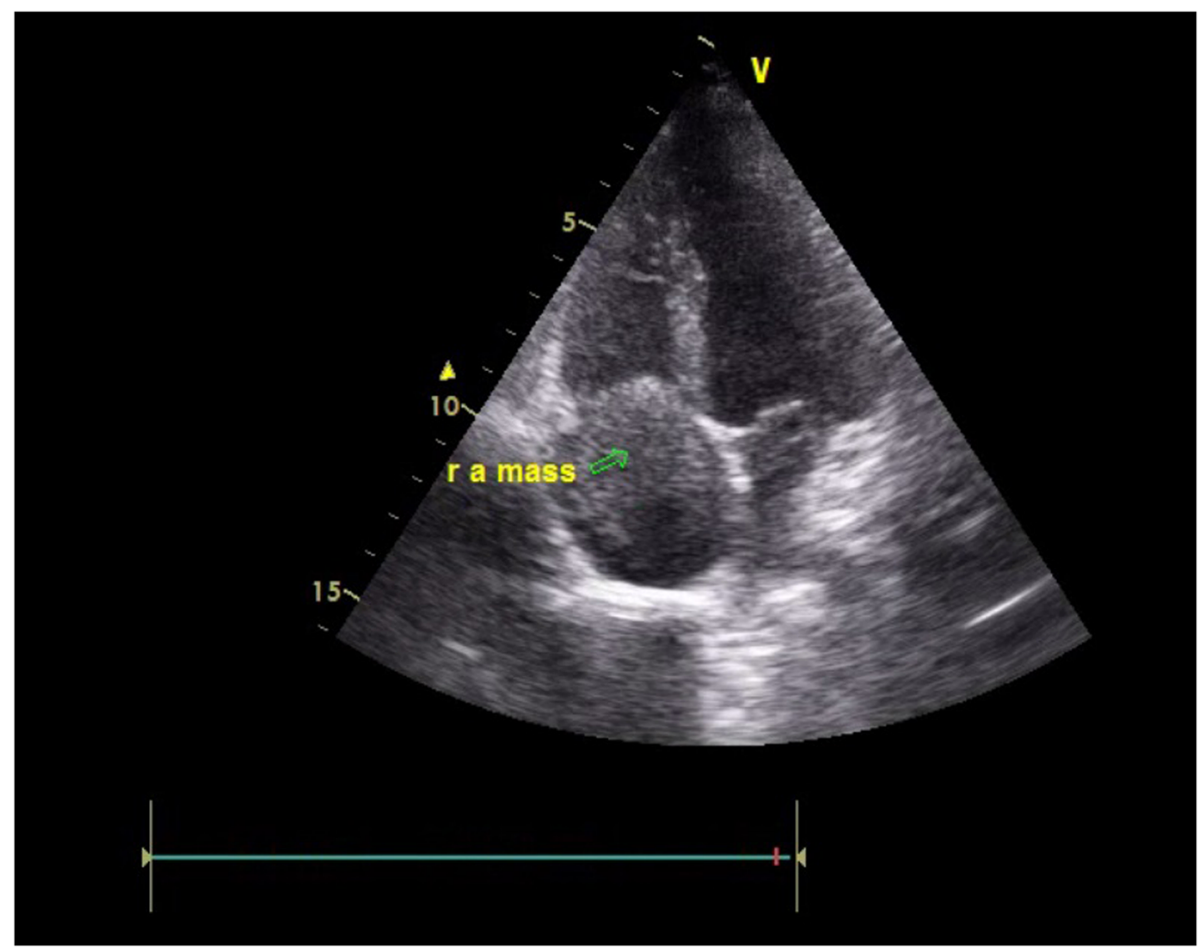

Fig. 2 2D-echocardiographic image showing the rt. atrial mass bulging into the rt. ventricle through the tricuspid valve 
Additional file 1: Figure S1 a, b and c, Addional file 3). Both kidneys were normal.

During the pre-anesthetic evaluation, trans-thoracic echo was performed (Fig. 2) which revealed a mass of 3 $\times 2 \mathrm{~cm}$ bulging into the right ventricle across the tricuspid valve, no intra-atrial attachments were visualized.

Contrast-enhanced CT (Fig. 3b; Additional file 2: Figure S2a and b) was done to assess the route and extent of involvement, which revealed multiple heterogeneously enhancing soft-tissue masses in the IVC (inferior vena cava) which was dilated. This mass was seen extending through the IVC into the right atrium. The right-sided ureter was compressed by this mass leading to right-sided hydroureteronephrosis.

Exploratory laparotomy was done and tumor presented in common, external, and internal iliac veins and IVC was removed (Fig. 4a, b). On pathological examination, the tumor consisted of pathologically benign smooth-muscle cells with prominent vascularization, as is typical for IVL.

Based on the clinical, imaging and surgical findings a diagnosis of intravenous leiomyomatosis (IVL) with intracardiac extension was made (Additional file 3).

\section{Discussion}

Intravenous leiomyomatosis occurs usually at a mean age of 47 years, and more than half (approximately $60 \%$ ) of patients have a history of a prior hysterectomy for uterine fibroids, as was also seen in the present case $[1,2]$.

Clinically, the presentation of ICLM can be quite variable. Though the condition may be detected incidentally in asymptomatic patients, the majority of cases present clinically with cardiovascular symptoms like breathlessness, tachycardia, syncope, palpitations, abdominal pain and distention, and/or lower extremity edema [1-3].

Our patient presented with signs and symptoms of heart failure, most likely due to intracardiac extension of tumor.

The diagnosis of IVL calls for a high index of clinical suspicion in combination with imaging features. Less than 300 cases have been described in the English medical literature, with the extension of the tumor into the heart in about 100 cases [4]. However, its actual incidence is probably more as it is usually misdiagnosed or not recognized in its early stages.

The role of sonography in IVL is limited to initial screening or recognizing intravascular mass or other intra-abdominal abnormality like hydronephrosis, in symptomatic patients which necessitates other investigations. While echocardiography may be of use in cases with intracardiac extension, cross-sectional imaging by CT scan and/or MRI is invariably required for defining the presence and extent of the tumor. Contrast-enhanced CT and CT angiography can help determine tumor extent and
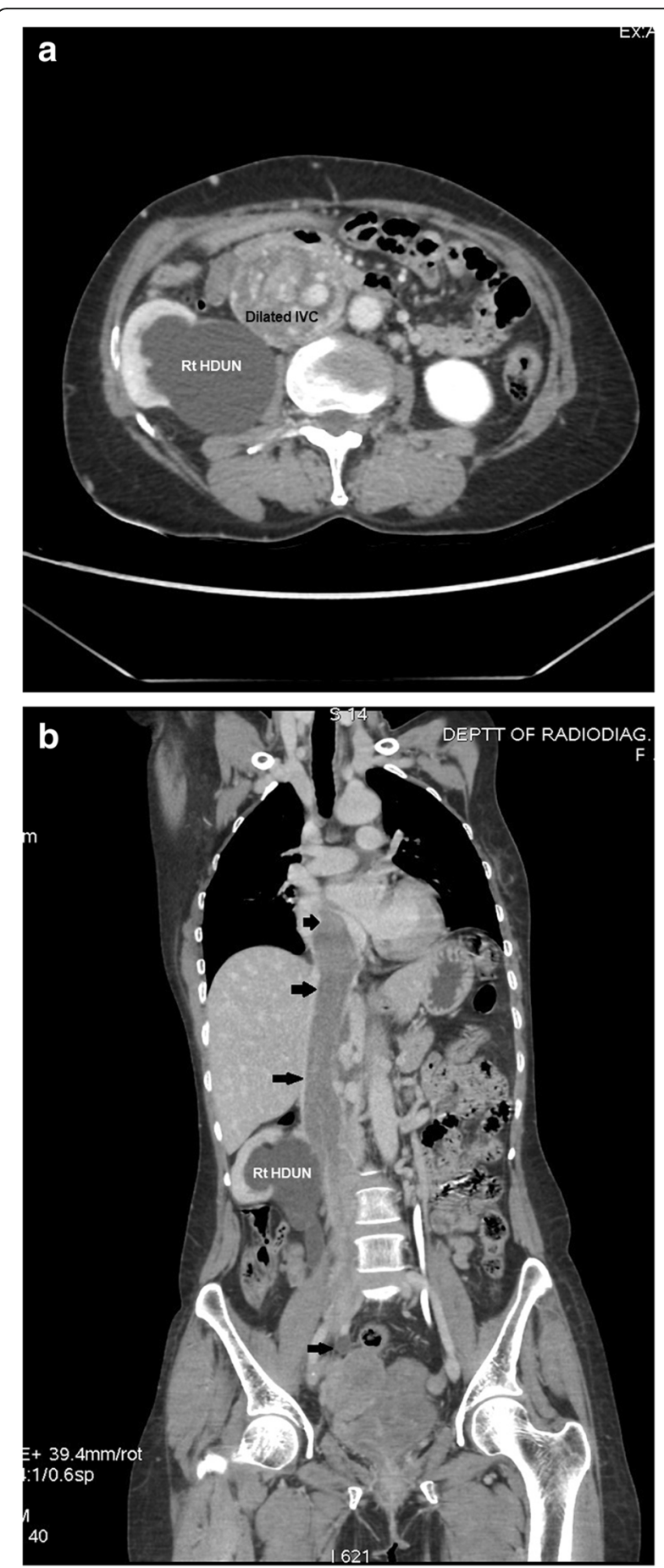

Fig. 3 CECT axial (a) and coronal (b) images revealing a dilated IVC (arrows) extending into the right ventricle. Dilated IVC compressed upon rt. ureter to cause rt. hydroureteronephrosis (Rt HDUN)

cardiac involvement $[1,4,5]$ The typical CECT appearance of the mass can range from hypo- to hyperenhancing, depending upon the timing of imaging and inherent blood supply of the tumor [6] Magnetic resonance imaging (MRI) can be of added benefit in 

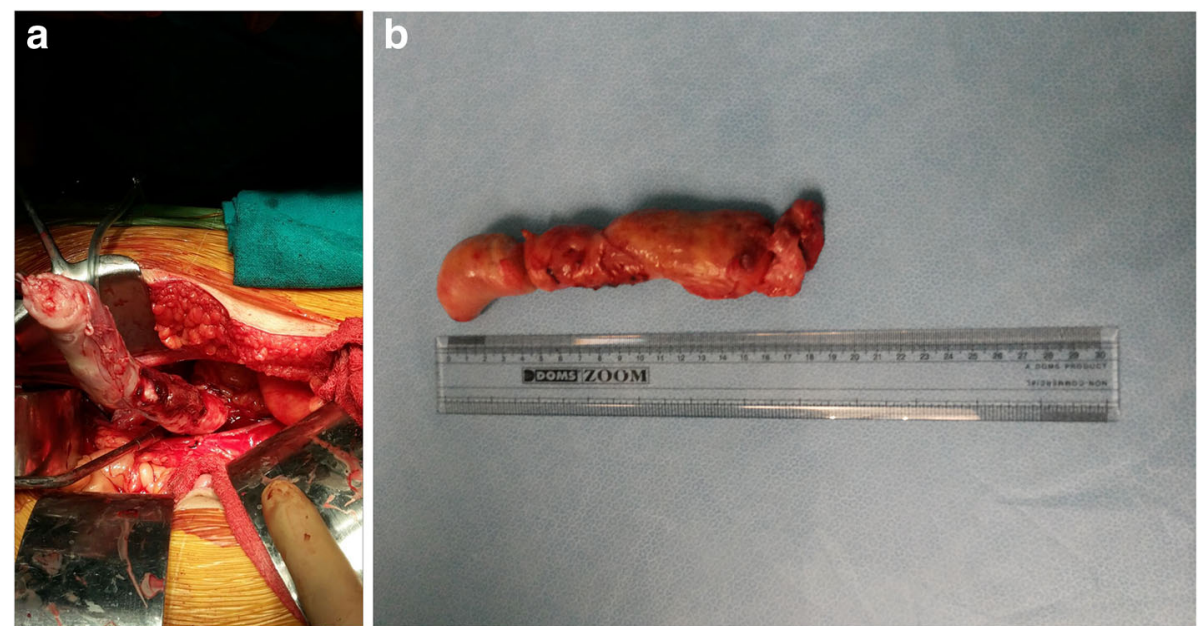

Fig. 4 Intracaval mass removed by exploratory laparotomy

localization of the tumor, its characterization, and in defining the tumor extent, due to its superior softtissue contrast resolution with the added advantage of being non-invasive, unlike $\mathrm{CT}$ which uses ionizing radiations [4]. It is also of use in cases where the use of contrast is contraindicated like in renal failure or when allergic to contrast.

On MRI, bland thrombus appears as a low signal intensity area on $\mathrm{T} 2$-weighted images due to the $\mathrm{T} 2$ shortening of blood decomposition products; whereas tumor thrombus shows intermediate to increased signal intensity on T2-weighted sequences. Diffusionweighted imaging (DWI) is a promising MR technique which is increasingly being used to differentiate malignant from bland thrombi (without the use of contrast media); tumor thrombus will show restricted diffusion similar to the primary tumor $[6,7]$.

On contrast-enhanced imaging, the bland thrombus will not enhance, whereas tumor thrombus will show enhancement and will be associated with the primary tumor.

The differential diagnosis of intravenous leiomyomatosis (intravascular mass showing enhancement on cross-sectional imaging) is leiomyosarcomas. Though it is not easy to differentiate these entities on imaging alone, sarcomas tend to be more aggressive and generally invade and extend outside the vessel walls and involve adjacent organs.

\section{Management}

Complete surgical removal of the tumor is the procedure of choice in the management of intravenous leiomyomatosis. Total abdominal hysterectomy and bilateral salpingo-oophorectomy should also be done (if not already done) to take care of the stimulatory effects of estrogen. A multidisciplinary surgical team or a two-stage surgical approach may be required, depending on the pre-operative status of the patient and the extent of the tumor and/or the involvement of adjacent organs.

Though pathologically benign, intravenous leiomyomatosis may have aggressive biologic and imaging features. Therefore, diagnosing this rare condition requires a high index of clinical suspicion and imaging correlation on contrast-enhanced CT scans and/ or MRI. Usually, surgical removal of the tumor in its entirety is required, which may be combined with neoadjuvant hormonal therapy such as tamoxifen or $\mathrm{GnRH}$ agonists, to take care of the associated estrogenic stimulatory effects. However, in spite of local tumor excision, recurrence is not uncommon (reported to be as high as $30 \%$ ); therefore, regular clinical and imaging follow-up is recommended [7].

Due to the rarity and the atypical presentation of this condition, there is a high chance of clinical misdiagnosis. Thus, awareness of this condition by radiologists, gynecologists, physicians, and surgeons is of vital importance for proper and timely diagnosis of this potentially fatal but treatable condition.

\section{Conclusion}

In conclusion, the diagnosis of IVL should be considered in a female if she presents with a soft mass in the systemic veins, with or without extension to the right heart chamber, especially in patients with a history of uterine myoma. Furthermore, imaging modalities able to display the precise location and extent of the tumor, such as CT and MRI, are of great importance in the pre-operative assessment of IVL. Using a single-stage approach is a safe and effective method of tumor extraction in selected patients. 


\section{Supplementary information}

Supplementary information accompanies this paper at https://doi.org/10. 1186/s43055-020-00159-5.

Additional file 1: Figure S1. Axial (a) and longitudinal (b) color Doppler ultrasound images depicting dilated IVC with intra-mural thrombus $(\mathrm{m})$ showing partial re-canalisation with extension into the right heart (c)

Additional file 2: Figure S2. CECT Axial (a ) and sagittal (b) images revealing a dilated IVC with heterogeneously enhancing mass extending into the right ventricle (arrows)

Additional file 3. Supplementary video. Ultrasound clip showing the mass extending into the right heart.

\section{Abbreviations}

IVC: Inferior vena cava; ICLM: Intracardiac leiomyomatosis; IVL: Intravenous leiomyomatosis; CT: Computed tomography; CECT: Contrast-enhanced computed tomography; MRI: Magnetic resonance and imaging;

$\mathrm{GnRH}$ : Gonadotropin-releasing hormone

\section{Acknowledgements}

The authors gratefully acknowledge the departments of CTVS (cardiothoracic and vascular surgery), Medicine and Pathology IGMC Shimla, who all worked in co-operation on this rare case.

\section{Authors' contributions}

RB contributed to the data collection, study design, manuscript writing, and revision. VT contributed to the data collection and study design. YSV reviewed the manuscript. SB contributed to the data collection, study design, and manuscript writing. AT and RP contributed to the data collection and study design. SS contributed to the analysis and critically reviewed the manuscript. All authors have read and approved the manuscript.

\section{Funding}

All the authors declare no funding or financial support.

\section{Availability of data and materials}

The datasets used and/or analyzed during the current study are available from the corresponding author on reasonable request.

\section{Ethics approval and consent to participate}

Any experimental investigation with human beings at work was obtained with informed consent and complied with the ethical guidelines of the institution and the Helsinki Declaration of 1975 and its October 2000 revision. The study did not involve the use of animals. The manuscript has not been submitted to any other journal/site in part or in whole for consideration. It is solely submitted to this journal.

\section{Consent for publication}

Written informed consent was obtained from the patient for publication of this case report.

\section{Competing interests}

The abstract of this manuscript has been presented as a poster at the KCR (Korean Congress of Radiology) 2016 at Seoul by Dr. Rohit Bhoil. The authors declare that they have no competing interests.

\section{Author details}

${ }^{1}$ Department of Radiodiagnosis, IGMC, Shimla, India. ${ }^{2}$ Department of cardiac-anaesthesia, IGMC, Shimla, India. ${ }^{3}$ Department of Cardio-thoracic and vascular surgery, IGMC, Shimla, India.

Received: 27 November 2019 Accepted: 26 February 2020

Published online: 09 March 2020

\section{References}

1. Li R, Shen Y, Sun Y, Zhang C, Yang Y, Yang J et al (2014) Intravenous leiomyomatosis with intracardiac extension: echocardiographic study and literature review. Tex Heart Inst J. 41:502-506
2. Castagneto Gissey L, Mariano G, Musleh L, Lepiane P, Colasanti M, Meniconi $\mathrm{RL}$ et al (2017) Massive pelvic recurrence of uterine leiomyomatosis with intracaval-intracardiac extension: video case report and literature review. BMC Surg. 17:118

3. Gunderson CC, Parsons B, Penaroza S, Peyton MD, Landrum LM (2016) Intravenous leiomyomatosis disguised as a large deep vein thrombosis. J Radiol Case Rep. 31:29-35

4. Oliveira L, Ramos S (2013) Anesthetic approach for a clinical case of intravenous leiomyomatosis: case report. Rev Bras Anestesiol. 63:504-507

5. Subramaniam B, Pawlowski J, Gross BA, Kim YB, Logrefo FW (2006) TEEguided onestage excision of intravenous leiomyomatosis with cardiac extension through an abdominal approach. J CardiothoracVascAnesth. 20:94-95

6. Kullo I, Gary L, Keeney B (1999) Intracardiacleiomyomatosis: echocardiographic features. Chest. 115:587-591

7. Liu B, Liu C, Guan H, Li Y, Song X, Shen K et al (2009) Intravenous leiomyomatosis with inferior vena cava and heart extension. J Vasc Surg. 50:897-902

\section{Publisher's Note}

Springer Nature remains neutral with regard to jurisdictional claims in published maps and institutional affiliations.

\section{Submit your manuscript to a SpringerOpen ${ }^{\circ}$ journal and benefit from:}

- Convenient online submission

- Rigorous peer review

- Open access: articles freely available online

- High visibility within the field

- Retaining the copyright to your article

Submit your next manuscript at $\boldsymbol{\nabla}$ springeropen.com 